\title{
Characterisation of an acapsular mutant of Burkholderia pseudomallei identified by signature tagged mutagenesis
}

\author{
TIMOTHY ATKINS, RICHARD PRIOR, KERRI MACK, PAUL RUSSELL, MICHELLE NELSON, \\ JOANN PRIOR, JILL ELLIS, PETRA C. F. OYSTON, GORDON DOUGAN* and \\ RICHARD W. TITBALL $\dagger$
}

Defence Science and Technology Laboratory, CBS Porton Down, Salisbury, Wiltshire, SP4 OJQ, *Department of Biological Sciences, Centre for Molecular Microbiology and Infection, Flowers Building, Imperial College of Science Technology and Medicine, Exhibition Road, London, SW7 2AY and †Department of Infectious and Tropical Diseases, London School of Hygiene and Tropical Medicine, Keppel Street, London WC1E 7HT

\begin{abstract}
A Burkholderia pseudomallei mutant which was attenuated in a mouse model of melioidosis was identified by a signature tagged mutagenesis approach. The transposon was shown to be inserted into a gene within the capsular biosynthetic operon. Compared with the wild-type bacteria this mutant demonstrated a $10^{5}$-fold increase in the median lethal dose in a mouse model and it did not react with a monoclonal antibody against high mol. wt polysaccharide of $B$. pseudomallei. To determine the kinetics of infection, mice were dosed intraperitoneally (i.p.) and intravenously (i.v.) with mutant and wildtype bacteria. After i.p challenge, the number of mutant bacteria in the peritoneal cavity declined, whereas wild-type bacteria proliferated. When administered by the i.v. route, the mutant was able to cause disease but the time to death was increased compared with the wild type. Mice were dosed with the mutant and subsequently challenged with wildtype $B$. pseudomallei, but the mutant failed to induce a protective immune response.
\end{abstract}

\section{Introduction}

Burkholderia pseudomallei is the causative agent of melioidosis, a severe disease of man and animals [1]. The bacterium is present in the environment, mainly in south-east Asia, Northern Australia, parts of Africa and South and Central America [2-4]. Although, historically, melioidosis has been considered relatively rare, the disease is being recognised in an increasing number of countries and with an increasing frequency $[5,6]$. This is probably due to a combination of factors, such as recent improvements in diagnostic techniques, a greater awareness of the disease and an increase in global travel from areas of the world where melioidosis is endemic. Melioidosis can present in a number of forms varying from acute septicaemia, acute pulmonary, subacute and chronic disease [1,7-9]. In some cases a latent infection is established which may cause disease in later life. The factors that influence the

Received 5 Nov. 2001; revised version accepted 21 Jan. 2002.

Corresponding author: Dr T. Atkins (e-mail: TPATKINS@, dstl.gov.uk). outcome of disease are not known, but differences in the virulence of strains $[8,10]$ might be important. A recent report has indicated that as well as the virulence of the strain, factors such as inoculum size of the infecting strain and host predisposition may also play a role in susceptibility to the disease [11]. Melioidosis is seen most frequently in diabetics, those with impaired cellular immunity or those with a history of drug or alcohol abuse, suggesting that differences in the immunological status of the host might also influence the outcome of the disease $[7,12]$.

Currently, little is known about the virulence mechanisms of $B$. pseudomallei. Work to identify virulence factors may be complicated by the possibility that disease might be dependent on the strains studied and the choice of animal model. Several studies in the 1950s reported that culture supernatant fluid was toxic for both mice and hamsters $[7,13]$ and that the level of production of toxin was strain-dependent $[13,14]$. A $31-\mathrm{kDa}$ cytotoxic protein $[15,16]$, a cytolethal peptide and a cytotoxic rhamnolipid $[17,18]$ have been reported to be produced by the organism. Several other extracellular products such as proteases, haemolysins 
and phospholipases [7, 19] have also been suggested as candidate toxins but their role in the pathogenesis of disease is unclear. Furthermore, the finding that a general secretion pathway mutant of $B$. pseudomallei retained virulence for Syrian hamsters [7] suggests that, at least in this model of disease, proteins exported by this pathway do not play a significant role.

Components of the outer membrane have also been considered as virulence determinants. B. pseudomallei produces two types of lipopolysaccharide (LPS) termed OPSI and OPSII and a capsular polysaccharide $[20,21]$. OPSII appears to play a role in resistance to serum killing and virulence in the diabetic rat model of infection $[22,23]$. The polysaccharide capsule also appears to be an important virulence factor, and a transposon mutant that failed to produce exopolysaccharide was markedly attenuated in Syrian hamsters [24].

Signature tagged mutagenesis (STM) has been used successfully in several bacterial pathogens to identify virulence determinants in vivo [25-33]. Briefly, a pool of transposons is assembled, each harbouring a unique oligonucleotide tag. Tagged bacterial mutants are grouped into pools and used to infect an animal model. Comparison of the oligonucleotide tags present in the pool before animal challenge with the tags present in the pool of mutants after animal passage indicates those mutants that have not survived passage in the animal. These mutants can be further characterised to identify genes that are specifically associated with virulence.

This study set out to identify bacterial mutants of $B$. pseudomallei with lesions in virulence determinants by STM. In the longer term this information could be used to develop vaccines or to identify targets for novel antimicrobial agents effective against melioidosis.

\section{Materials and methods}

\section{Chemicals, enzymes and bacterial strains}

Chemicals and enzymes were obtained from the SigmaAldrich Chemical Company (Poole, Dorset) unless otherwise stated. B. pseudomallei strain 576 was used throughout this project. It was isolated initially from a clinical case of fatal melioidosis in Thailand, and provided by Dr T. Pitt, Central Public Health Laboratory, Colindale, London. B. pseudomallei was cultured at $37^{\circ} \mathrm{C}$ in Luria Bertani (LB) broth medium supplemented as required with antibiotics [34].

\section{Animal studies}

$\mathrm{BALB} / \mathrm{c}$ and Porton Outbred (PO) mice were agematched, c. 6-week-old females. Stock animals were grouped together in cages of five with free access to food and water and subjected to a 12-h light/dark cycle. After challenge, the animals were handled under bio-safety level III containment conditions within a half-suit isolator, compliant with British Standard BS5726. All investigations involving animals were performed according to the requirements of the Animal (Scientific Procedures) Act 1986. The median lethal dose (MLD) was calculated by the method of Reed and Muench [35].

To determine protection against wild-type challenge, mice surviving the MLD experiment were challenged with $1 \times 10^{4} \mathrm{cfu}$ of $B$. pseudomallei strain 576 . Intravenous (i.v.) challenges were administered by warming the mice with an infra-red bulb before injection via the tail vein.

\section{Signature tagged mutagenesis (STM)}

STM was performed as described previously [25]. $B$. pseudomallei strain 576 was transformed by electroporation $(2.5 \mathrm{kV}, 200 \mathrm{Ohm}, 25 \mu \mathrm{F}$ capacitance) with a BioRad Gene Pulser II (BioRad Laboratories, Hemel Hempstead, Herts) with plasmid pUTminTn5Km2 which had been modified to incorporate one of 96 tags. Cells were prepared for electroporation by repeatedly washing in sterile glycerol $10 \% \mathrm{v} / \mathrm{v}$. After electroporation, the cells were allowed to recover for $3 \mathrm{~h}$ at $37^{\circ} \mathrm{C}$ with shaking $(220 \mathrm{rpm})$ and then plated on LB agar containing kanamycin $700 \mu \mathrm{g} / \mathrm{ml}$. B. pseudomallei is resistant to ampicillin, preventing detection of the loss of the suicide plasmid DNA by screening for ampicillin-sensitive, kanamycin-resistant clones. To ensure plasmid DNA loss, randomly selected bacterial mutants were screened by PCR for the loss of the nucleotide sequence encoding the transposase enzyme necessary for transposon integration. No mutants were identified which had the transposase gene sequence, indicating complete loss of the suicide plasmid DNA. One pool of 96 transposon mutants was assembled and used to challenge groups of five PO mice by the intraperitoneal (i.p.) route in this preliminary screen. After incubation for $72 \mathrm{~h}$ in vivo the mice were killed by cervical dislocation and the spleens were removed and homogenised in $2 \mathrm{ml}$ of LB broth and plated on LB agar. Plates were incubated overnight and c. 10000 colonies were harvested. DNA was purified and used in a PCR to amplify the tags. This PCR product was radiolabelled and used in Southern blots [34] to probe for all possible tags. Comparison of tags present before animal passage with tags present after animal passage indicated those tags which were absent from the pool of mutants recovered from the animal.

\section{Competition index}

B. pseudomallei strain 576 and transposon mutant 1E10 were cultured in broth to $c .1 \times 10^{8} \mathrm{cfu} / \mathrm{ml}$. Each culture was serially diluted and the cultures were mixed to provide an inoculum containing $4.46 \times 10^{2} \mathrm{cfu}$ of $B$. pseudomallei strain 576 and $2.39 \times 10^{2}$ cfu of $B$. 
pseudomallei mutant 1E10. Samples of the inoculum were plated on LB agar to calculate total viable bacteria and on LB agar supplemented with kanamycin $700 \mu \mathrm{g} / \mathrm{ml}$ to calculate the number of B. pseudomallei mutant 1E10 organisms. Unsupplemented plates were incubated for $24 \mathrm{~h}$ at $37^{\circ} \mathrm{C}$; supplemented plates were incubated for $48 \mathrm{~h}$.

Groups of five PO mice were challenged with the mixed inoculum by the i.p. route of infection. At $72 \mathrm{~h}$ after challenge, the mice were killed by cervical dislocation. The spleens were homogenised in $2 \mathrm{ml}$ of LB broth and plated on LB agar with or without antibiotic. The plates were incubated at $37^{\circ} \mathrm{C}$ for $18 \mathrm{~h}$ and the numbers of mutant and wild-type bacteria were counted on LB agar with or without kanamycin.

\section{Cloning of the genomic region interrupted by the transposon in B. pseudomallei $1 E 10$}

DNA was prepared from $100-\mathrm{ml}$ cultures of $B$. pseudomallei in LB broth by a lysozyme, phenolchloroform extraction method [36] and digested with SacI restriction endonuclease. The digested DNA was purified with Microcon 100 (Millipore UK, Watford) spin columns and ligated with similarly pre-digested pUC19 plasmid DNA. The ligation was purified with Microcon 100 spin columns and used to transform Escherichia coli Sure cells (Stratagene Europe, Amsterdam, The Netherlands) by electroporation. After recovery, the E. coli were plated on LB agar supplemented with kanamycin $50 \mu \mathrm{g} / \mathrm{ml}$. Colonies were selected after incubation for $24 \mathrm{~h}$ at $37^{\circ} \mathrm{C}$. Plasmid DNA was re-isolated with a Qiagen mini-prep kit and used in sequencing reactions with commercially available oligonucleotide primers which hybridised to the multiple cloning site.

\section{Deoxynucleotide sequencing}

Sequencing was performed with the Taq Dyedeoxy ${ }^{\mathrm{TM}}$ kit supplied by Applied Biosystems (Warrington). Approximately $4.8 \mathrm{pmol}$ of oligonucleotide primer was used in each sequencing reaction along with $500 \mathrm{ng}$ of recombinant plasmid, or $100 \mathrm{ng}$ of PCR product. Excess terminators were removed by ethanol precipitation before the nucleotide sequence was determined with a DNA sequencer model 373A (Applied Biosystems). Sequencing results were analysed on Apple Macintosh computers with Applied Biosystems Data Analysis software.

\section{Immunoblotting of $B$. pseudomallei strains 576 and 1 E10 with a monoclonal antibody}

B. pseudomallei strains 576 or $1 \mathrm{E} 10$ were cultured in $\mathrm{LB}$ broth for $18 \mathrm{~h}$ at $37^{\circ} \mathrm{C}$ and harvested by centrifugation $\left(10000 \mathrm{~g}, 10 \mathrm{~min}, 4^{\circ} \mathrm{C}\right)$. A suspension of $B$. pseudomallei strain 576 or strain $1 \mathrm{E} 10(32 \mathrm{mg} / \mathrm{ml})$ was digested with proteinase $\mathrm{K}$ [37] and $7.5 \mu \mathrm{l}$ of the digest were used for each lane of a gel. The samples were separated by SDS-PAGE through an acrylamide $10 \%$ w/v gel [38] and blotted with a semi-dry transfer system. After blocking with bovine serum albumin (BSA) $5 \% \mathrm{w} / \mathrm{v}$ overnight and washing for $3 \times 5 \mathrm{~min}$ in BSA $0.1 \% \mathrm{w} / \mathrm{v}$, the blotted membranes were probed with monoclonal antibody (MAb) 4VIH12 [39] diluted 1 in 25 in BSA $0.1 \% \mathrm{w} / \mathrm{v}$ for $1-2 \mathrm{~h}$ at room temperature. This was followed by three 5 -min washes in BSA $0.1 \% \mathrm{w} / \mathrm{v}$. A sheep anti-mouse Auroprobe ${ }^{\mathrm{TM}}$ antibody (Amersham Pharmacia Biotech) was diluted 1 in 100 in water containing gelatin (1 in 20 dilution) and applied for $1-2 \mathrm{~h}$. The blot was then washed twice for $5 \mathrm{~min}$ in BSA $0.1 \% \mathrm{w} / \mathrm{v}$ and twice for $5 \mathrm{~min}$ in phosphate-buffered saline (PBS) prepared by the method of Dulbecco A (Fisher Scientific). Equal amounts of the silver enhancer and initiator (Amersham Pharmacia Biotech) were applied and the blot was agitated until colour developed.

\section{Immunofluorescent staining}

Bacterial suspensions were diluted to $1 \times 10^{9} \mathrm{cfu} / \mathrm{ml}$ in distilled water and $40 \mu \mathrm{l}$ of the suspension were placed on a glass coverslip and allowed to dry. The coverslips were washed briefly in PBS before immersing in acetone for $2 \mathrm{~min}$. After fixing, the coverslips were washed in PBS before incubating in fetal calf serum $5 \% \mathrm{v} / \mathrm{v}$ in PBS (FCS/PBS) for $2 \mathrm{~h}$ to block non-specific binding. After three 2-min washes in PBS, the coverslips were incubated with MAb 4VIH12 $(1 \mu \mathrm{g} / \mathrm{ml}$ in FCS/PBS $5 \% \mathrm{v} / \mathrm{v}$ ) for $1 \mathrm{~h}$ at $37^{\circ} \mathrm{C}$ and, after three further washes in PBS, they were incubated with antimouse fluorescein isothiocyanate (FITC) conjugate (diluted 1 in 64 ) for $1 \mathrm{~h}$ at $37^{\circ} \mathrm{C}$. The coverslips were washed three times for $2 \mathrm{~min}$ in PBS and mounted on glass slides with aqueous glycerol $92 \% \mathrm{v} / \mathrm{v}$. Slides were examined by phase-contrast and fluorescent microscopy with an Olympus Fluoview Laser scanning microscope.

\section{Results}

Signature tagged mutagenesis of B. pseudomallei

Purified plasmid pUTminiTn5Km2, which had been modified to incorporate one of 96 tags, was transformed into B. pseudomallei strain 576 by electroporation. In total, 2000 signature tagged mutants were generated and stored frozen until required. A pool of 96 individual bacterial mutants, each harbouring unique nucleotide tags, was assembled and three groups of three PO mice were infected with $1 \times 10^{4} \mathrm{cfu}$ by the i.p. route. After $48 \mathrm{~h}$, bacteria recovered from the spleens were used to prepare DNA, which was used as a template in the PCR to amplify nucleotide tags. The tags were radiolabelled and used in a Southern blot against amplified nucleotide tags from the input pool. Comparison of the membrane probed with the tags from the input pool with the membrane probed with the tags from the recovered pool indicated signature tags 
which were not present in the recovered pool (data not shown). Some variation in the pattern of elimination of bacteria by individual animals was seen. However, one bacterial mutant (1E10) was identified which was consistently absent from the recovered pool of bacteria from all three animals.

Previous studies with other bacterial pathogens have indicated that c. $2-4 \%$ of signature tagged mutants will be attenuated by the i.p. route of infection. During this study one bacterial mutant was isolated from a pool of 96 mutants, which was lost from the bacterial population during animal passage. However, other signature tags displayed reduced signal strengths, possibly indicating that these mutants were attenuated, but to a lesser extent than B. pseudomallei mutant $1 \mathrm{E} 10$.

\section{Confirmation of attenuation by competition index}

Three mice were challenged by the i.p. route with $100 \mu \mathrm{l}$ of a mixture of $1 \times 10^{2}$ cfu of $B$. pseudomallei 576 and $1 \times 10^{2} \mathrm{cfu}$ of $B$. pseudomallei $1 \mathrm{E} 10$. After $72 \mathrm{~h}$ the bacteria in the spleens were enumerated on LB agar with and without kanamycin supplementation. Whereas in the challenge inoculum the ratio of strain 576 to strain $1 \mathrm{E} 10$ was 1.86 , the ratio for the two strains, respectively, recovered from splenic tissues was $<9.17 \times 10^{9}$. From these results a competition index of $<2.02 \times 10^{-10}$ was calculated (Table 1). This confirmed that mutant $1 \mathrm{E} 10$ was attenuated compared with the wild-type strain by the i.p. route of infection and no viable cells of the mutant were recovered from any of the mice.

\section{Identification of the gene interrupted in B. pseudomallei mutant $1 E 10$}

Total genomic DNA was prepared from the mutant 1E10, digested with SacI and ligated into pUC19. Kanamycin-resistant colonies were selected, as these would possess plasmids with inserts containing the transposon, which were then sequenced. The deduced amino acid sequence was used to search the GenBank database with TBLASTN. The closest match was indicated as the mannosyltransferase from Zymomonas mobilis $\left(e^{-31}\right)$. The nucleotide sequences surrounding the putative mannosyltransferase gene were obtained from the B. pseudomallei K96243 genome sequencing project (http://www.sanger.ac.uk/projects/B_pseudomallei).
A map of this region of the B. pseudomallei genome was deduced and was found to be the capsular polysaccharide operon described for $B$. pseudomallei $1026 \mathrm{~b}$ [21]. The structure of the capsular polysaccharide of $B$. pseudomallei has been reported previously to contain mannose [40]. Therefore, it is likely that the transposon inserted into the genome of mutant strain $1 \mathrm{E} 10$ abolished its ability to synthesise capsular polysaccharide by preventing mannose from assembling into the KDO region of the capsular polysaccharide.

\section{Confocal microscopy with MAbs}

A hybridoma cell line that secretes MAb antibody $4 \mathrm{VIH} 12$, reactive with cell surface polysaccharide, was generated previously in this laboratory. B. pseudomallei wild-type and 1E10 mutant cells were exposed to MAb 4VIH12 and an FITC-labelled anti-mouse secondary antibody and visualised by confocal microscopy. The antibody bound to the outer surface of strain 576 cells (Fig. 1a) but did not bind to the mutant (Fig. 1b). Phase-contrast microscopy confirmed the presence of bacterial cells in each of the samples. These findings indicate that the mutant $1 \mathrm{E} 10$ cells failed to produce a surface-located polysaccharide.

\section{LPS and high mol. wt polysaccharide in B. pseudomallei strain $1 E 10$}

Polysaccharide material was prepared from B. pseudomallei strains 576 and 1E10 and analysed by SDSPAGE. A characteristic banding pattern typical of LPS was observed in both preparations (Fig. 2a). Western blots of similar gels were also probed with MAb 4VIH12 which bound to a high mol. wt component in the extract of strain 576 but failed to react with the strain 1E10 extract (Fig. 2b). These findings indicate that B. pseudomallei mutant $1 \mathrm{E} 10$ had lost the ability to produce capsular polysaccharide but retained the ability to produce LPS.

\section{Growth of B. pseudomallei strain 576 and B. pseudomallei mutant $1 E 10$ in vivo}

In PO mice, the MLD of B. pseudomallei 1E10 by the i.p. route was calculated as $>1 \times 10^{6} \mathrm{cfu}$. No animal deaths occurred in the group of animals that received $1 \times 10^{6} \mathrm{cfu}$ and a higher dose was not given because of the risk of death due to endotoxic shock. The MLD of

Table 1. Confirmation of attenuation of mutant B. pseudomallei $1 \mathrm{E} 10$ by competition index with wild-type strain 576

\begin{tabular}{lccccc}
$\begin{array}{l}\text { Animal } \\
\text { no. }\end{array}$ & $\begin{array}{c}\text { B. pseudomallei } \\
576 \text { input cfu }\end{array}$ & $\begin{array}{c}\text { B. pseudomallei } \\
\text { 1E10 input cfu }\end{array}$ & $\begin{array}{c}\text { B. pseudomallei } \\
576 \text { recovered cfu }\end{array}$ & $\begin{array}{c}\text { B. pseudomallei } \\
\text { 1E10 recovered cfu* }\end{array}$ & $\begin{array}{c}\text { Competition index } \\
\text { (CI) }\end{array}$ \\
\hline 1 & $4.46 \times 10^{2}$ & $2.39 \times 10^{2}$ & $9.17 \times 10^{9}$ & 0 & $<1.09 \times 10^{-10}$ \\
2 & $4.46 \times 10^{2}$ & $2.39 \times 10^{2}$ & $6.15 \times 10^{9}$ & 0 & $<1.6 \times 10^{-10}$ \\
3 & $4.46 \times 10^{2}$ & $2.39 \times 10^{2}$ & $6.4 \times 10^{9}$ & 0 & $<1.5 \times 10^{-10}$ \\
& & & & Average CI & $<1.39 \times 10^{-10}$ \\
\hline
\end{tabular}

* No viable bacteria were recovered but a value of 1 was assigned to calculate a ratio. 

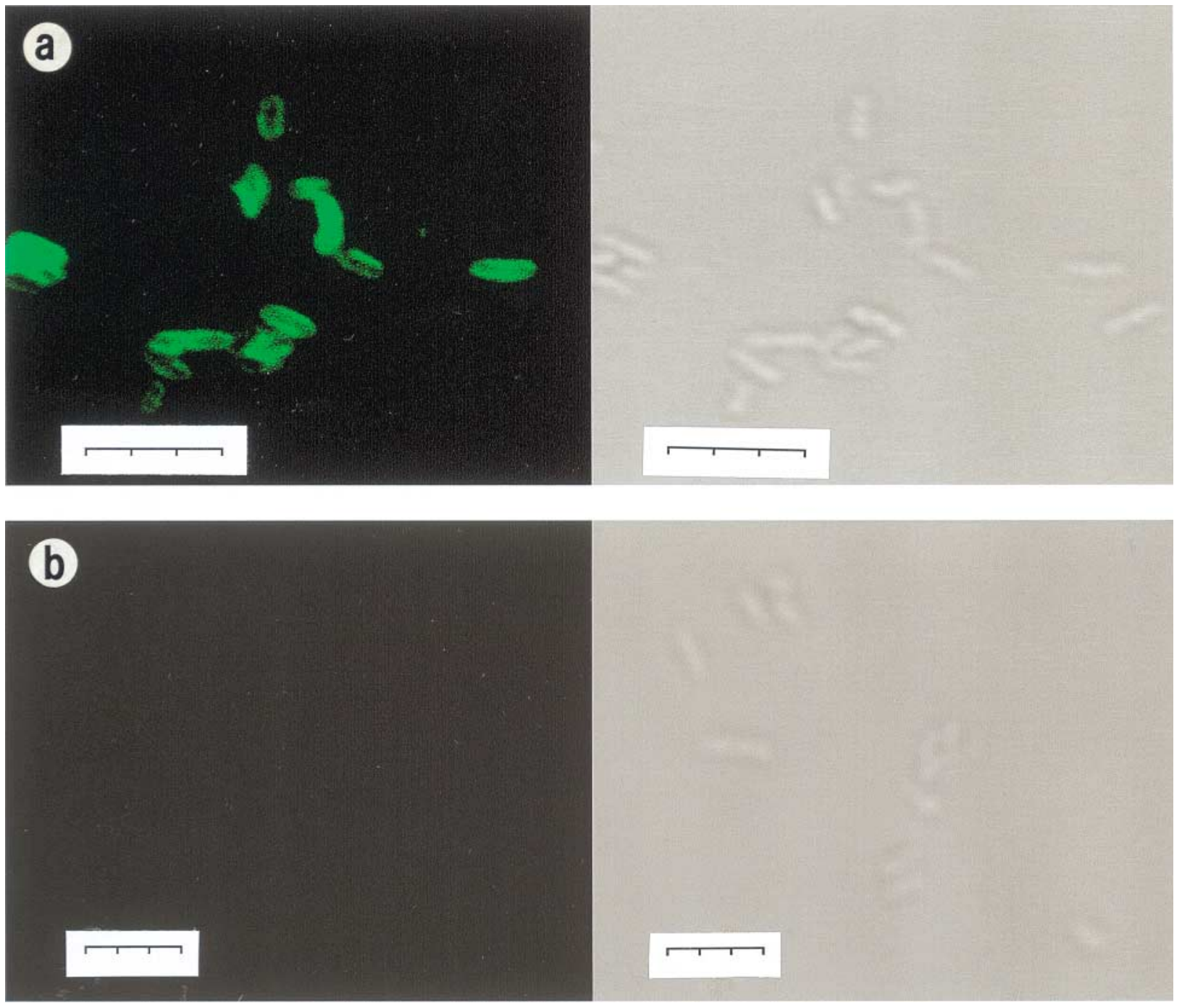

Fig. 1. Binding of a MAb to high mol. wt polysaccharide of B. pseudomallei strains 576 and $1 \mathrm{E} 10$ demonstrated by confocal and phase-contrast microscopy. a, B. pseudomallei 576 ; b, B. pseudomallei $1 \mathrm{E} 10$

strain 576 was $7 \mathrm{cfu}$. Mice that received $1 \times 10^{6} \mathrm{cfu}$ of the mutant $1 \mathrm{E} 10$ were challenged 35 days later with $1 \times 10^{4} \mathrm{cfu}$ of strain 576 and all succumbed to infection.

To investigate the pattern of survival and growth of $B$. pseudomallei 576 or B. pseudomallei 1E10, c. $1 \times$ $10^{3} \mathrm{cfu}$ of each strain were administered i.p. to groups of $10 \mathrm{BALB} / \mathrm{c}$ mice. At set time points one animal from each group was killed and bacteria in the peritoneal cavity or spleen were recovered. The numbers of strain 576 increased over the course of the experiment, whereas strain $1 \mathrm{E} 10$ organisms declined to a level below the limit of detection by $36 \mathrm{~h}$ after infection (Fig. 3). Furthermore, the numbers of strain 576 or $1 \mathrm{E} 10$ bacteria in the spleens increased until $6 \mathrm{~h}$ after challenge. The mutant strain increased more rapidly than the parent strain. Beyond $6 \mathrm{~h}$, the numbers of the mutant declined over the next $48 \mathrm{~h}$. In contrast, the wild-type bacteria increased in number throughout the experiment (data not shown).

Virulence of B. pseudomallei 1E10 by the i.v. challenge route

Groups of five PO mice were inoculated with a high dose of $9 \times 10^{7} \mathrm{cfu}$ or a low dose of $9 \times 10^{5} \mathrm{cfu}$ of strains $1 \mathrm{E} 10$ or 576 by the i.v. route of infection. After 19 days all mice had died. Mice challenged with the high dose of strain 1E10 showed an extended time to death compared with mice challenged with a similar dose of strain 576, which died after just 3 days. Mice challenged with the lower dose of strain 1E10 also displayed an increase in time to death compared with the control group (Fig. 4). However, challenge with either strain by the i.v. route resulted in the sudden death of the animal without symptoms of disease. This was in contrast to mice infected with strain 576 by the 
a

1

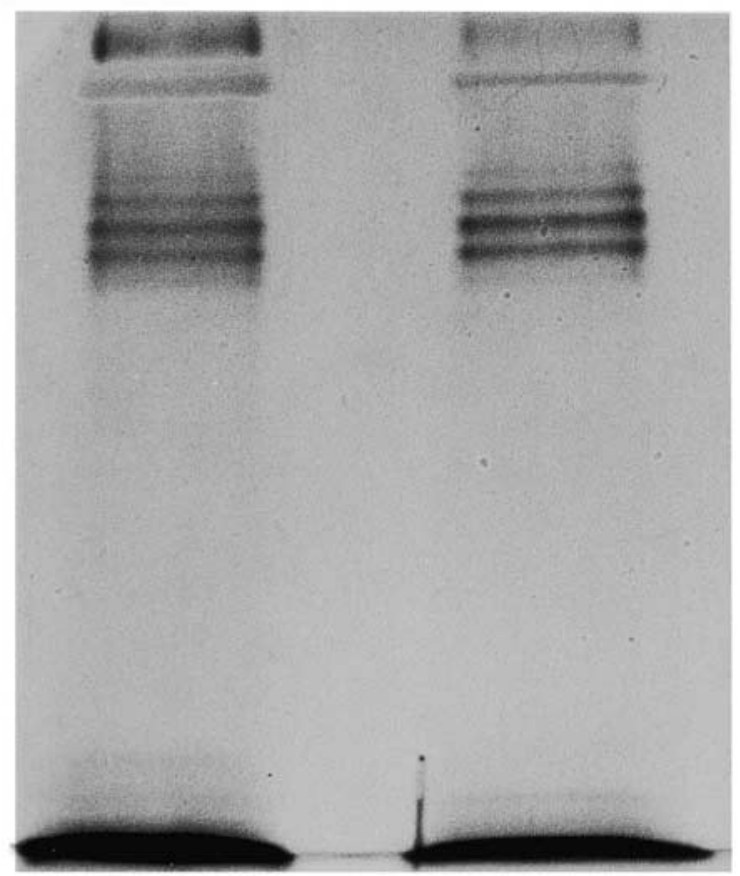

b

$$
1
$$

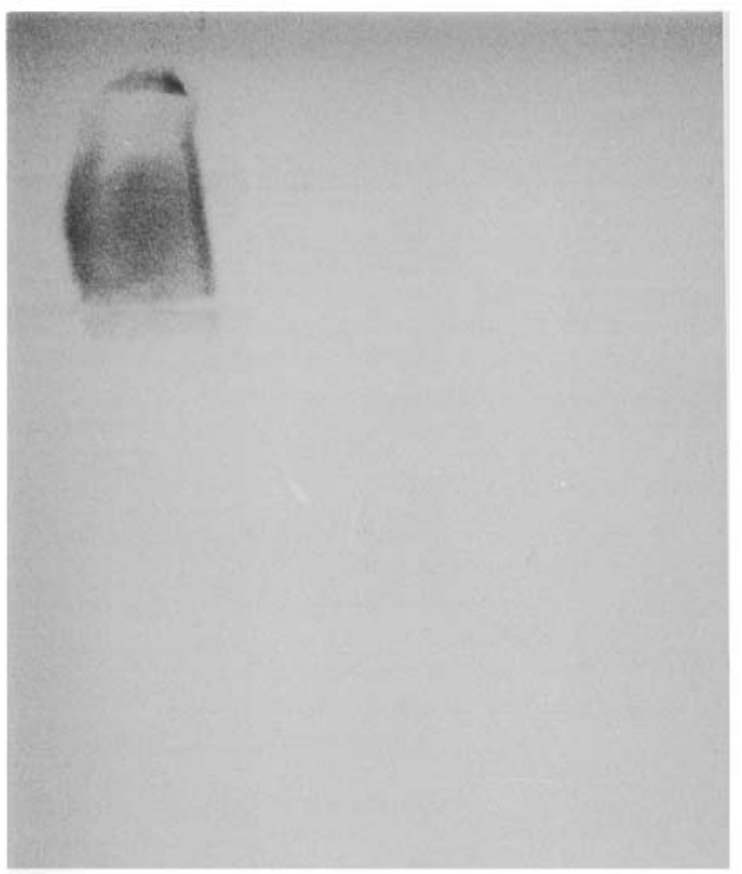

Fig. 2. (a) SDS-PAGE of polysaccharide extracts of B. pseudomallei. Lane 1, strain 576; 2, strain 1E10. (b) Immunoblotting of polysaccharide extracts of $B$. pseudomallei with MAb to high mol. wt polysaccharide. Lane 1, strain 576; 2, strain 1 E10.

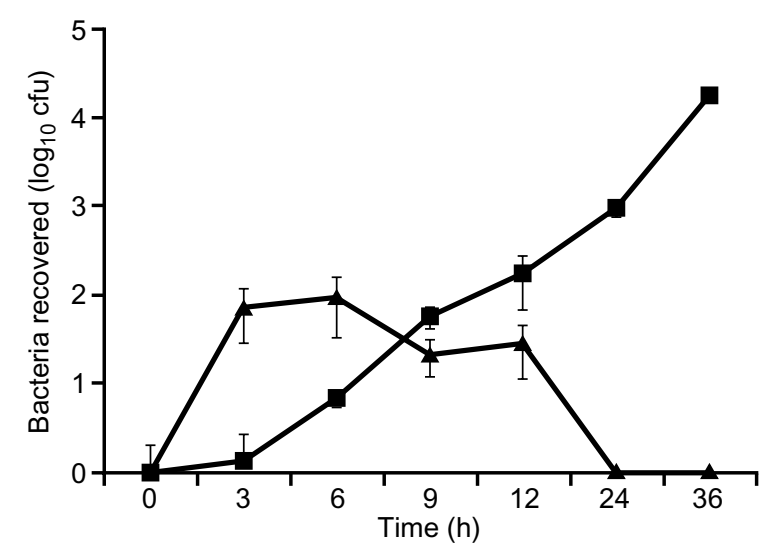

Fig. 3. Clearance of B. pseudomallei from mouse peritoneum over time. Strain 576, $\mathbf{\square}$; strain 1E10, $\mathbf{\Delta}$.

i.p. route, which showed symptoms such as ruffled fur and paralysis of the hind limbs before death occurred.

\section{Discussion}

STM has been used successfully for several bacterial pathogens as a method of identifying virulence determinants. However, the successful use of the technique is reliant on the availability of an animal model of disease for a population of bacteria to be screened simultaneously. With some pathogens and some animal models of disease, either clonal selection or non-specific clonal elimination of the input pool occurs early in the infection process resulting in low representation of signature-tagged mutants in the output pool $[26,41,42]$. Some workers have resolved these problems by reducing the complexity of the input pool to $48[41,43]$. Even when these problems can be resolved, it is important to harvest infected tissues at an appropriate time after challenge to allow disadvantaged mutants to be eliminated. Overall, these findings indicate that the successful use of STM requires optimisation of the system and it will not be suitable for use with all pathogens [42]. In this study, a murine model of melioidosis was developed in which it was possible to screen a pool of 96 mutants. No problems with clonality were observed and one attenuated mutant, 1E10, was identified. The method reported here could now be used for more extensive studies to identify additional virulence determinants of $B$. pseudomallei. However, if secreted virulence factors are important in pathogenicity, it is possible that they would not be identified by this technique because of cross-complementation of mutant phenotype by other members of the challenge population [42].

On the basis of sequence homology, the gene interrupted in B. pseudomallei 1E10 was identified as encoding a putative mannosyltransferase enzyme. The electrophoretic profile of LPS from the wild-type and mutant strains were identical, suggesting that the enzyme was involved in capsule rather than LPS biosynthesis. The mutant $1 \mathrm{E} 10$ failed to bind an antibody reactive with high mol. wt polysaccharide which indicated that it is unable to produce capsular 


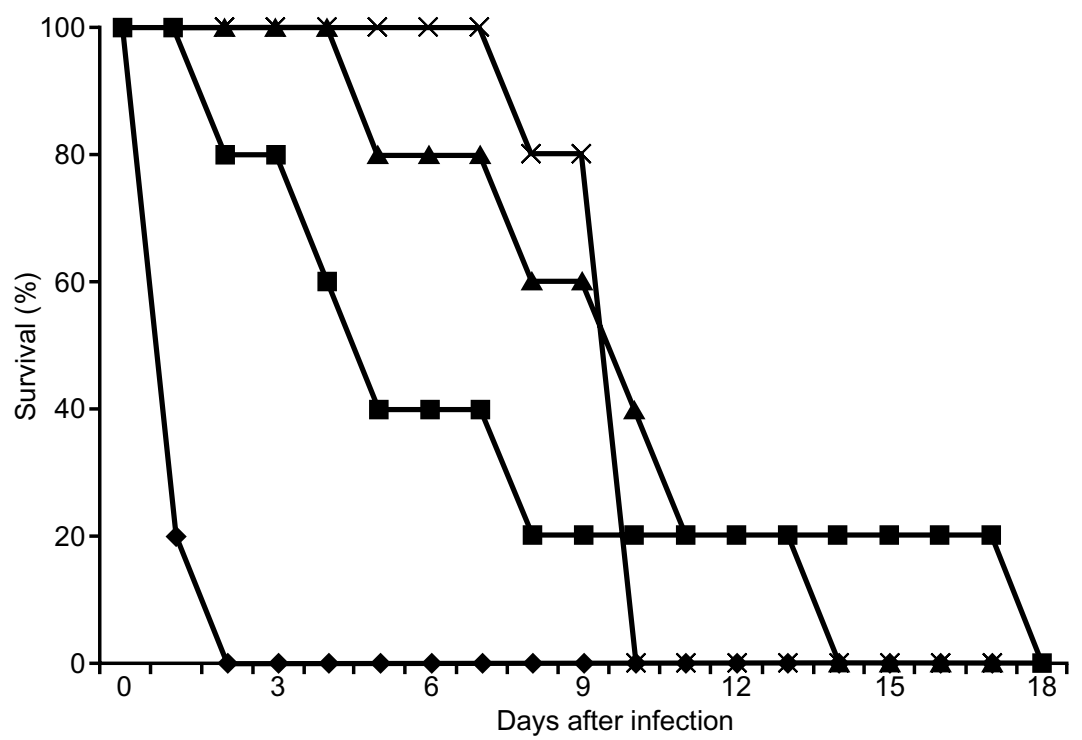

Fig. 4. Survival of mice infected with B. pseudomallei in relation to inoculum. Strain 576 at inoculum $9.15 \times 10^{7} \mathrm{cfu}(\bullet)$, $9.15 \times 10^{5} \mathrm{cfu}(\boldsymbol{\square})$; strain 1 E10 at inoculum $8.8 \times 10^{7} \mathrm{cfu}(\mathbf{\Delta}), 8.8 \times 10^{5} \mathrm{cfu}(\times)$.

polysaccharide. Previous work has shown that a mutant derived from B. pseudomallei strain $1026 \mathrm{~b}$ that was unable to produce capsular polysaccharide was attenuated in a Syrian hamster model of disease [21]. The results of the present study confirm this and indicate that a capsule-negative mutant is also attenuated in the mouse. The capsule is also important for virulence of the related pathogen $B$. mallei [24] and a non-capsulate mutant has been shown to be attenuated in the hamster model of disease. Searching the mannosyltransferase gene interrupted in B. pseudomallei 1E10 against the K96243 genome sequence database showed that the gene is part of the capsular operon described by Reckseidler et al. [21]. This operon is large, comprising 20 potential open reading frames, yet the gene inactivated in the present study is the same as one of only five transposon mutants which were isolated from 1300 mutants in the earlier study [21]. This suggests that this gene may be a hot-spot for transposition. Hotspotting of transposon insertion events can occur in areas of a bacterial genome that differ in their GC base ratio when compared with the whole genome [44, 45]. $B$. thailandensis, a close but non-capsulate relative of B. pseudomallei [46], has recently been shown to possess a truncated capsule polysaccharide operon [24] with truncation close to the insertion site of the transposon in B. pseudomallei 1E10. This lack of a capsule may be one reason that $B$. thailandensis strains are avirulent in mouse models.

After i.p. challenge of mice, both wild-type and mutant bacteria could be recovered from the i.p. cavity and bacteria appeared in splenic tissues soon after challenge. $B$. pseudomallei has been reported previously to be a facultative intracellular pathogen, and tissues taken from infected animals or human patients frequently reveal bacteria within professional and nonprofessional phagocytic cells [47-49]. The finding in the present study that bacteria appeared within spleens after i.p. challenge confirms the findings of other studies $[49,50]$. The numbers of $B$. pseudomallei $1 \mathrm{E} 10$ bacteria in the peritoneal cavity or in spleens were higher than the numbers of wild-type bacteria in these tissues $3 \mathrm{~h}$ after challenge, suggesting that the mutant possessed a growth advantage early in infection. This may be due to a reduced biochemical burden with the mutant not having to expend energy in synthesising the capsule, but this was not indicated by the in-vitro competition index experiment where mutant and wildtype bacteria grew equally well. However, after this time the numbers of strain 1E10 declined, presumably due to serum or macrophage killing of ingested bacteria. In contrast, the numbers of $B$. pseudomallei strain 576 increased. The polysaccharide capsules produced by many pathogens appear to play a role in resistance to phagocyosis [51-53]. However, it has been reported that capsulate and genetically undefined non-capsulate $B$. pseudomallei are equally susceptible to uptake by polymorphonuclear phagocytes [7]. Within phagocytes, capsulate bacteria appear to be resistant to phagocyte killing mechanisms and are able to replicate $[54,55]$. Therefore, the precise role of the polysaccharide capsule in virulence of $B$. pseudomallei requires further study.

In some bacterial species, such as Actinobacillus pleuropneumoniae [56] and Erysipelothrix rhusiopathiae [57], non-capsulate mutants have been shown to have potential as candidate live attenuated vaccines. However, in this study, mice that received even $10^{6} \mathrm{cfu}$ of strain 1E10 were not protected against a subsequent challenge with $1 \times 10^{4} \mathrm{cfu}$ of strain 576 . Preliminary studies have indicated that a MAb against a high mol. wt polysaccharide is able to provide some protection against experimental melioidosis [58]. The finding that the non-capsulate mutant of $B$. pseudomallei does not 
induce protection against infection may indicate that capsular polysaccharide is a major protective antigen expressed by this pathogen.

Although attenuated by the i.p. route, when given by the i.v. route $B$. pseudomallei $1 \mathrm{E} 10$ caused a lethal infection, although the time to death was markedly extended in comparison with wild-type bacteria. Mice that had been challenged by the i.v. route with this mutant showed symptoms of disease different from those seen after i.p challenge with this mutant or after i.p or i.v. challenge with the wild-type strain. The rapidity with which death followed the appearance of symptoms suggests a toxin-mediated disease. It seems unlikely that this effect was due to the release of LPS from the challenge inoculum, because deaths were not recorded until at least 7 days after challenge. Some forms of melioidosis are characterised by the rapid onset of symptoms and it has been suggested that toxins produced by the bacterium play a role in the pathogenesis of this form of the disease [17]. Whether toxins are responsible for the deaths of mice seen after i.v. challenge with B. pseudomallei $1 \mathrm{E} 10$ is not clear at this time.

In summary, this study has developed a method to allow the use of signature tagged mutagenesis with the bacterial pathogen $B$. pseudomallei. It has shown that the capsular polysaccharide is a major virulence determinant in this organism and it is probably a major protective antigen. The finding that a noncapsulate mutant of $B$. pseudomallei was still virulent by the i.v. route of infection demonstrates that virulence in this organism is multifactorial, perhaps reflecting the diverse nature of melioidosis in man.

The authors wish to thank Dr Gill Hartley for assistance with the confocal microscope, Margaret Morley, Dougie Brown and Debbie Bell for technical assistance in their areas of expertise. We also thank Dr Jackie Shea for plasmid pUTminiTn5Km2 and for advice on the STM technique.

\section{References}

1. Leelarasamee A, Bovornkitti S. Melioidosis: review and update. Rev Infect Dis 1989; 11: 413-425.

2. Dance DAB. Melioidosis. Rev Med Microbiol 1990; 1: $143-150$.

3. Batchelor BIF, Paul J, Trakulsomboon S, Mgongo M, Dance DAB. Melioidosis survey in Kenya. Trans $R$ Soc Trop Med Hyg 1994; 88: 181.

4. Yabuuchi E, Arakawa M. Burkholderia pseudomallei and melioidosis: be aware in temperate area. Microbiol Immunol 1993; 37: 823-836.

5. Chen Y, Peng C, Hwang K, Tsai J, Lu P, Chen T. An indigenous melioidosis: a case report. Kaohsiung J Med Sci 1999; 15: 292-296.

6. Mathew S, Perakath B, Mathew G et al. Surgical presentation of melioidosis in India. Natl Med J India 1999; 12: 59-61.

7. Brett PJ, Woods DE. Pathogenesis of and immunity to melioidosis. Acta Trop 2000; 74: 201-210.

8. Howe C, Sampath A, Spotnitz M. The pseudomallei group: a review. J Infect Dis 1971; 124: 598-606.

9. Beeker A, Van de Stadt KD, Bakker K. Melioidosis. Neth J Med 1999; 54: 76-79.

10. Dance DAB. Pseudomonas pseudomallei: danger in the paddy fields. Trans $R$ Soc Trop Med Hyg 1991; 85: 1-3.

11. Ulett GC, Currie BJ, Clair TW et al. Burkholderia pseudomallei virulence: definition, stability and association with clonality. Microbes Infect 2001; 3: 621-631.

12. Puthucheary SD, Parasakthi N, Lee MK. Septicaemic melioidosis: a review of 50 cases from Malaysia. Trans $R$ Soc Trop Med Hyg 1992; 86: 683-685.

13. Colling M, Nigg C, Heckly RJ. Toxins of Pseudomonas pseudomallei. 1. Production in vitro. J Bacteriol 1958; 76: $422-426$.

14. Nigg C, Heckly RJ, Colling M. Toxin produced by Malleomyces pseudomallei. Proc Soc Exp Biol Med 1955; 89: $17-20$.

15. Mohamed R, Nathan S, Embi N, Razak N, Ismail G. Inhibition of macromolecular synthesis in cultured macrophages by Pseudomonas pseudomallei exotoxin. Microbiol Immunol 1989; 33: 811-820.

16. Ismail G, Noor Embi M, Omar O, Allen JC, Smith CJ. A competitive immunosorbent assay for detection of Pseudomonas pseudomallei exotoxin. $J$ Med Microbiol 1987; 23: $353-357$.

17. Haase A, Janzen J, Barrett S, Currie B. Toxin production by Burkholderia pseudomallei strains and correlation with severity of melioidosis. J Med Microbiol 1997; 46: 557-563.

18. Häubler S, Nimtz M, Domke T, Wray V, Steinmetz I. Purification and characterization of a cytotoxic exolipid of Burkholderia pseudomallei. Infect Immun 1998; 66: 1588-1593.

19. Ashdown LR, Koehler JM. Production of hemolysin and other extracellular enzymes by clinical isolates of Pseudomonas pseudomallei. J Clin Microbiol 1990; 28: 2331-2334.

20. Isshiki Y, Matsuura M, Dejsirilert S, Ezaki T, Kawahara K. Separation of 6-deoxy-heptane from a smooth-type lipopolysaccharide preparation of Burkholderia pseudomallei. FEMS Microbiol Lett 2001; 199: 21-25.

21. Reckseidler SL, Deshazer D, Sokol PA, Woods DE. Detection of bacterial virulence genes by subtractive hybridisation: identification of capsular polysaccharide of Burkholderia pseudomallei as a major virulence determinant. Infect Immun 2001; 69: 34-44.

22. Woods DE, Jones AL, Hill PJ. Interaction of insulin with Pseudomonas pseudomallei. Infect Immun 1993; 61: 4045-4050.

23. DeShazer D, Brett PJ, Woods DE. The type II O-antigenic polysaccharide moiety of Burkholderia pseudomallei lipopolysaccharide is required for serum resistance and virulence. Mol Microbiol 1998; 30: 1081-1100.

24. DeShazer D, Waag DM, Fritz DL, Woods DE. Identification of a Burkholderia mallei polysaccharide gene cluster by subtractive hybridization and demonstration that the encoded capsule is an essential virulence determinant. Microb Pathog 2001; 30: 253-269.

25. Hensel M, Shea JE, Gleeson C, Jones MD, Dalton E, Holden DW. Simultaneous identification of bacterial virulence genes by negative selection. Science 1995; 269: 400-403.

26. Darwin AJ, Miller VL. Identification of Yersinia enterocolitica genes affecting survival in an animal host using signaturetagged transposon mutagenesis. Mol Microbiol 1999; 32: $51-62$.

27. Mei J-M, Nourbakhsh F, Ford CW, Holden D. Identification of Staphylococcus aureus virulence genes in a murine model of bacteraemia using signature-tagged mutagenesis. Mol Microbiol 1997; 26: 399-407.

28. Polissi A, Pontiggia A, Feger G et al. Large-scale identification of virulence genes from Streptococcus pneumoniae. Infect Immun 1998; 66: 5620-5629.

29. Zhao H, Li X, Johnson DE, Mobley HLT. Identification of protease and rpoN-associated genes of uropathogenic Proteus mirabilis by negative selection in a mouse model of ascending urinary tract infection. Microbiology 1999; 145: 185-195.

30. Camacho LR, Ensergueix D, Perez E, Gicquel B, Guilhot G. Identification of a virulence gene cluster of Mycobacterium tuberculosis by signature-tagged transposon mutagenesis. Mol Microbiol 1999; 34: 257-267.

31. Foulongne V, Bourg G, Cazevieille C, Michaux-Charachon S, O'Callaghan D. Identification of Brucella suis genes affecting intracellular survival in an in vitro human macrophage infection model by signature-tagged transposon mutagenesis. Infect Immun 2000; 68: 1297-1303.

32. Hong PC, Tsolis R, Ficht TA. Identification of genes required for chronic persistence of Brucella abortus in mice. Infect 
Immun 2000; 68: 4102-4107.

33. Brown JS, Aufauvre-Brown A, Jennings JM, Arst H, Holden DW. Signature-tagged and directed mutagenesis identify PABA synthetase as essential for Aspergillus fumigatus pathogenicity. Mol Microbiol 2000; 36: 1371-1380.

34. Sambrook J, Fritsch EF, Maniatis T. Molecular cloning. A laboratory manual, 2nd edn. Cold Spring Harbor, NY, Cold Spring Harbor Laboratory Press. 1989: 3, A1-A6.

35. Reed LJ, Muench H. A simple method of estimating fifty percent endpoints. Am J Hyg 1938; 27: 493-497.

36. Mack K, Titball RW. The detection of insertion sequences within the human pathogen Burkholderia pseudomallei which have been identified previously in Burkholderia cepacia. FEMS Microbiol Lett 1998; 162: 69-74.

37. Chart H. Lipopolysaccharide: isolation and characterization. In: Chart H (ed) Methods in practical laboratory bacteriology. Boca Raton, CRC Press. 1994: 11-20.

38. Laemmli UK. Cleavage of structural proteins during the assembly of the head of bacteriophage T4. Nature 1970; 227: $680-685$

39. Ellis J. Antibody detection of Burkholderia pseudomallei and Burkholderia mallei. PhD thesis, Aston University, Birmingham. 2000: 291.

40. Steinmetz I, Reganzerowski A, Brenneke B, Häussler S, Simpson A, White NJ. Rapid identification of Burkholderia pseudomallei by latex aggultination based on an exopolysaccharide-specific monoclonal antibody. J Clin Microbiol 1999; 37: $225-228$.

41. Chiang SL, Mekalanos JJ. Use of signature-tagged transposon mutagenesis to identify Vibrio cholerae genes critical for colonization. Mol Microbiol 1998; 27: 797-805.

42. Perry RD. Signature-tagged mutagenesis and the hunt for virulence factors. Trends Microbiol 1999; 7: 385-388.

43. Autret A, Dubail I, Trieu-Cuot P, Berche P, Charbit A. Identification of new genes involved in the virulence of Listeria monocytogenes by signature-tagged transposon mutagenesis. Infect Immun 2001; 69: 2054-2065.

44. Berg DE, Weiss A, Crossland L. Polarity of Tn5 insertion mutations in Escherichia coli. J Bacteriol 1980; 142: 439-446.

45. Berg DW, Schmandt M, Lowe JB. Specificity of transposon Tn5 insertion. Genetics 1983; 105: 813-828.
46. Brett PJ, DeShazer D, Woods DE. Burkholderia thailandensis sp. nov., a Burkholderia pseudomallei-like species. Int J Syst Bacteriol 1998; 48: 317-320.

47. Wong KT, Puthucheary SD, Vadivelu J. The histopathology of human meliodosis. Histopathology 1995; 26: 51-55.

48. Jones AL, Beveridge TJ, Woods DE. Intracellular survival of Burkholderia pseudomallei. Infect Immun 1996; 64: 782-790.

49. Santanirand P, Harley VS, Dance DAB, Drasar BS, Bancroft GJ. Obligatory role of gamma interferon for host survival in a murine model of infection with Burkholderia pseudomallei. Infect Immun 1999; 67: 3593-3600.

50. Gauthier YP, Thibault FM, Paucod JC, Vidal DR. Protease production by Burkholderia pseudomallei and virulence in mice. Acta Trop 2000; 74: 215-220.

51. Noel GJ, Hoiseth SK, Edelson PJ. Type b capsule inhibits ingestion of Haemophilus influenzae by murine macrophages: studies with isogenic encapsulated and unencapsulated strains. $J$ Infect Dis 1992; 166: 178-182.

52. Nilsson I-M, Lee JC, Bremell T, Rydén C, Tarkowski A. The role of staphylococcal polysaccharide microcapsule expression in septicemia and septic arthritis. Infect Immun 1997; 65: 4216-4221.

53. Boyce JD, Adler B. The capsule is a virulence determinant in the pathogenesis of Pasteurella multocida M1404 (B:2). Infect Immun 2000; 68: 3463-3468.

54. Smith CJ, Allen JC, Embi MN, Othman O, Razak N, Ismail G. Human melioidosis: an emerging medical problem. MIRCEN $J$ 1987; 3: 343-366.

55. Pruksachartvuthi S, Aswapokee N, Thankerngpol K. Survival of Pseudomonas pseudomallei in human phagocytes. J Med Microbiol 1990; 31: 109-114.

56. Inzana TJ, Todd J, Veit HP. Safety, stability, and efficacy of noncapsulated mutants of Actinobacillus pleuropneumoniae for use as live vaccines. Infect Immun 1993; 61: 1682-1686.

57. Shimoji Y, Mori Y, Sekizaki T, Shibahara T, Yokomizo Y. Construction and vaccine potential of acapsular mutants of Erysipelothrix rhusiopathiae: use of excision of Tn916 to inactivate a target gene. Infect Immun 1998; 66: 3250-3254.

58. Steinmetz I, Nimtz M, Wray V, Häussler S, Reganzerowski A, Brenneke B. Exopolysaccharides of Burkholderia pseudomallei. Acta Trop 2000; 74: 211-214. 